\title{
Bonding to dentin as a function of air-stream temperatures for solvent evaporation
}

Andréia Aquino Marsiglio ${ }^{(a)}$ Júlio César Franco Almeida ${ }^{(\mathrm{b})}$ Leandro Augusto Hilgert ${ }^{(\mathrm{c})}$ Paulo Henrique Perlatti D'Alpino ${ }^{(\mathrm{d})}$ Fernanda Cristina Pimentel $\operatorname{Garcia}^{(\mathrm{c})}$

\footnotetext{
(a) Department of Operative Dentistry, School of Dentistry, Catholic University of Brasília UCB, Brasília, DF, Brazil.

(b) University Hospital of Brasília - HUB, University of Brasília - UnB, Brasília, DF, Brazil.

(c) Department of Operative Dentistry, School of Dentistry, University of Brasília - UnB, Brasília, DF, Brazil.

(d) Biomaterials Research Group, School of Dentistry, Anhanguera-Uniban University, São Paulo, SP, Brazil.
}

Declaration of Interests: The authors certify that they have no commercial or associative interest that represents a conflict of interest in connection with the manuscript.

Corresponding author:

Fernanda Cristina Pimentel Garcia

E-mail: garciafcp@unb.br

Received for publication on Nov 21, 2011 Accepted for publication on Feb 17, 2012
Abstract: This study evaluated the influence of solvent evaporation conditions of acid-etching adhesives. The medium dentin of thirty extracted human third molars was exposed and bonded to different types of etch-and-rinse adhesives: 1) Scotchbond Multi-Purpose (SBMP) - water-based; 2) Adper Single Bond 2 (SB) - ethanol/water-based, and 3) Prime \& Bond 2.1 (PB) - acetone-based. Solvents were evaporated at air-drying temperatures of $21^{\circ} \mathrm{C}$ or $38^{\circ} \mathrm{C}$. Composite buildups were incrementally constructed. After storage in water for $24 \mathrm{~h}$ at $37^{\circ} \mathrm{C}$, the specimens were prepared for bond strength testing. Data were analyzed by two-way ANOVA and Tukey's test (5\%). SBMP performed better when the solvents were evaporated at a higher temperature $(p<0.05)$. Higher temperatures did not affect the performance of SB or PB. Bond strength at room temperature was material-dependent, and air-drying temperatures affected bonding of the water-based, acid-etching adhesive.

Descriptors: Tensile Strength; Dentin-Bonding Agents; Dental Restoration, Permanent.

\section{Introduction}

Solvent evaporation represents an important clinical step during the dentin bonding, as the presence of high concentrations of solvent in some of these systems may compromise polymerization if they are not properly evaporated. ${ }^{1-2}$ Residual solvents may also directly affect the bond integrity providing pathways for nanoleakage. ${ }^{3-5}$ The resultant interfacial structures also become more hydrophilic, thus more prone to hydrolytic degradation. ${ }^{4,6-7}$ For that reason, it is essential to remove as much solvent as possible from the dentin surface prior to photoactivation. The general consensus is that solvents need to be evaporated from resin-infiltrated dentin matrix, as the residual solvents can lead to poor properties of the resulting polymer, ${ }^{3,8}$ and have an adverse effect on the polymerization of adhesives. ${ }^{1,9,10}$ As a consequence, solvents may have an impact on the quality and durability of bonding., ${ }^{4,11}$ Clinically, residual solvents can be avoided by allowing evaporation to take place between the application and the curing of the adhesive system.

The time allowed for evaporation of the solvent can have a significant effect on the bonding to dentin. ${ }^{12-14}$ This potential effect seems to depend on the type of solvent, tooth-syringe distance, air-blowing step and the temperature used to evaporate the solvent from the surface. ${ }^{1,12,14}$ The aim of this in vitro study was to evaluate the influence of the temperature at which the air-stream evaporates the solvents on the bonding of the adhesive to dentin. A variety of different commercial etch-and-rinse adhesives were selected for the present 
study, and the temperature at which the solvents were evaporated was varied: $21^{\circ} \mathrm{C}$ (room temperature) and $38^{\circ} \mathrm{C}$. The first research hypothesis to be tested was that the bond strength to dentin would be similar when the solvents in the adhesive formulations were evaporated at room temperature $\left(21^{\circ} \mathrm{C}\right)$ or at $38^{\circ} \mathrm{C}$. The second hypothesis to be tested was that the bond strength would be similar for all adhesive systems, irrespective of the air-stream temperature.

\section{Methodology}

\section{Specimen preparation}

Thirty sound human third molars were selected. Teeth were obtained and used in accordance with a protocol approved by the Research Ethics Committee. Teeth were stored in saline solution containing $0.1 \%$ Thymol at $4^{\circ} \mathrm{C}$ and used within 4 months after extraction. The cusps were abraded by using a water-cooled rotating diamond wheel (Isomet 1000, Buehler; Lake Bluff, USA) to expose a flat surface free of enamel tissue in the mid-coronal dentin surface. A standardized smear layer was produced by using a wet-ground silicon carbide paper for $60 \mathrm{~s}$ and then finished to \#600-grit. Subsequently, each exposed surface was acid-etched for $15 \mathrm{~s}$ with a $37 \%$ phosphoric acid gel and water-rinsed for the same length of time. The exposed dentin was rinsed with water and blotted dry with a cotton pellet, leaving a moist surface as directed by the manufacturer's instructions. The adhesive systems selected for the study are described in Table 1 along with their composition. A variety of etch-and-rinse adhesives were selected:

- a 3-step, water-based adhesive (Adper Scotchbond Multi Purpose - SBMP);

- a 2-step, acetone-based adhesive (Prime \& Bond 2.1 - PB); and

- a 2-step, ethanol/water-based adhesive (Adper Single Bond 2 - SB).

Bonding procedures were carried at room temperature $\left(21^{\circ} \mathrm{C}\right)$ and $60 \%$ relative humidity, as directed by the manufacturers.

The specimens were randomly divided into 2 groups $(n=10)$ based on the temperature at which solvent evaporation was to be performed. In one group, the solvent was evaporated, according to manufacturers directions, by thorough drying with clean, dry air from a dental syringe for at least $5 \mathrm{~s}$ (Table 1). The syringe tip was positioned at a distance of $2 \mathrm{~cm}$ from the specimens. A digital thermostat was used to monitor the temperature and constancy at which the air blow reached the specimens. The same procedures were carried out in the other group of specimens with the exception that the air

Table 1 - Chemical formulations of the adhesives applied and manufactures directions.

\begin{tabular}{c|c|c}
\hline Adhesive systems / Batch number & Composition & $\begin{array}{c}\text { Manufacturer's } \\
\text { directions }\end{array}$ \\
\hline $\begin{array}{c}\text { Adper Scotchbond Multi Purpose } \\
\text { (SBMP) }\end{array}$ & $\begin{array}{c}\text { Primer: 2-hydroxyethyl methacrylate (HEMA), } \\
\text { copolymer of polyalkenoic acid, water }\end{array}$ & $\mathrm{A}$ \\
(3M ESPE, St. Paul, USA) & Bond: bisphenol-a-glycidyl methacrylate & $\mathrm{C}$ \\
(7RB - 09/10) & (Bis-GMA), HEMA, camphorquinone & $\mathrm{D}$ \\
& & $\mathrm{E}$ \\
& Bond: Ethanol, water, Bis-GMA, MDP & $\mathrm{J}$ \\
\hline Adper Single Bond 2 & (10-10-methacryloyloxydecyl dihydrogen & $\mathrm{B}$ \\
(3M ESPE, St. Paul, USA) & phosphate), HEMA, silanated colloidal silica, & $\mathrm{F}$ \\
(7MN - 08/10) & glycerol 1,3 dimethacrylate, copolymer of & $\mathrm{G}$ \\
& polyalkenoic acid, camphorquinone & $\mathrm{I}$ \\
& & $\mathrm{J}$ \\
\hline Prime \& Bond 2.1 & Bond: Elastomeric dimethacrylate resin, & $\mathrm{A}$ \\
(Dentsply, Mildford, USA) & PENTA (dipentaerythritol penta acrylate & E \\
(2496 - 07/10) & monophosphate), photoinitiators, stabilizers, & $\mathrm{H}$ \\
& cetylamine hydrofluoride, acetone & $\mathrm{I}$ \\
\hline
\end{tabular}

A - acid- etch for $15 \mathrm{~s}$; B - rinse for $15 \mathrm{~s}$; C - apply the primer; D - air-dry for $5 \mathrm{~s}$; E - apply one coat of adhesive; $\mathrm{F}$ - apply two coats of adhesive; $\mathrm{G}$ - wait 15 seconds to facilitate evaporation of the solvent; $\mathrm{H}$ - wait $20 \mathrm{~s}$ to facilitate evaporation of the solvent; I - air-dry for $2-5 \mathrm{~s}$; J - light cure for $10 \mathrm{~s}$. 
was blown at a temperature of $38^{\circ} \mathrm{C}$ by a specific tooth dryer hand piece (A-dec, Newberg, USA). Briefly, the device utilizes pressure to force dry air to pass through a tube into two distinct swirling air streams. The pressure against the swirling system agitates air molecules to generate heat that warms the air that is blown out gently from the tip orifice.

The air temperature at the tip orifice is very high and cools gradually with increasing distance from the tip. Previous calibration procedures determined that the temperature of the air was constantly maintained at $38^{\circ} \mathrm{C}$ at a distance of $2 \mathrm{~cm}$ from the hand piece tip, at a constant pressure of 60 psi. Five teeth were randomly assigned per adhesive and solvent evaporation temperature. After the bonding procedures, resin build-ups (Filtek Z350, 3M ESPE, St. Paul, USA) were constructed onto the bonded surfaces by applying increments of $1 \mathrm{~mm}$ up to a height of $4 \mathrm{~mm}$. Each layer was photoactivated for $40 \mathrm{~s}$ by using a light curing unit that provided a power density of $500 \mathrm{~mW} / \mathrm{cm}^{2}$ (Demetron, Kerr Corp., Tacoma, USA). The specimens were stored in distilled water at $37^{\circ} \mathrm{C}$ for $24 \mathrm{~h}$ before testing.

\section{Microtensile bond strength testing}

The bonded teeth were longitudinally sectioned in both " $\mathrm{x}$ " and " $y$ " directions across the bonded interface using an Isomet saw (Buehler Ltd., Lake Bluff, USA) with cross-sectional area of approximately $1 \mathrm{~mm}^{2}$. Each beam was attached to a modified Bencor Multi-T testing apparatus (Danville Engineering Co., Danville, USA) with a cyanoacrylate resin (Zapit, DVA Inc., Corona, USA) and tested in tension in a universal testing machine (MTS 810, Eden Prairie, USA) operating at a crosshead speed of $0.5 \mathrm{~mm} / \mathrm{min}$. After testing, the crosssectional area at the site of fracture was measured with a digital caliper (Absolute Digimatic, Mitutoyo, Tokyo, Japan) to permit the calculation of the bond strengths in MPa. The distribution of failure mode of the remaining composite and dentin fragments was also evaluated at $40 \times$ magnification by using a dissecting microscope (Stereozoom, Bausch \& Lomb, Rochester, USA). Failure mode patterns were classified as follows:

- Adhesive $=$ adhesive between dentin and adhesive system;

- Cohesive in resin composite;

- Cohesive in dentin; and
- mixed (cohesive in resin composite and dentin).

Statistical analysis

Two-way ANOVA (factors were: adhesive system and temperature) was used to detect any significant differences. Tukey's test was used to analyze differences between the adhesive versus air-temperature. Significance level was pre-set at $\alpha=5 \%$.

\section{Results}

Results of the bond strength test are summarized in Table 2.

No significant interaction was noted between the factors "adhesive" and "temperature" $(\mathrm{P}=0.650)$. The bond strength of SBMP increased when the solvent evaporating step was performed at $38^{\circ} \mathrm{C}(\mathrm{p}<0.05)$. Bonding to dentin of both the SB and PB adhesives was not influenced by the higher temperature of air-blowing $(\mathrm{p}>0.05)$. At $21^{\circ} \mathrm{C}, \mathrm{PB}$ yielded the highest bond strength values, which were not significantly different from those of SB. When the bond strength at $38^{\circ} \mathrm{C}$ was compared, no significance was observed among the experimental groups $(p>0.05)$. Figure 1 presents the incidences of failure modes for all of the experimental groups. Failure mode evaluation demonstrated mostly adhesive mode of failure in all of the experimental groups. Both 2-step, etch-and-rinse adhesives (PB and SB adhesives) exhibited increased incidence of cohesive failures in resin composite when the evaporation temperature of the solvent was $38^{\circ} \mathrm{C}$.

\section{Discussion}

Various types of etch-and-rinse adhesives were selected for the present study based on the solvents present in their formulation. SBMP is a three-step, etch-

Table 2 - Average (SD) bond strength (MPa) for each adhesive as a function of the air temperature of the drying step.

\begin{tabular}{c|c|c}
\hline & $\begin{array}{c}\text { Air temperature } \\
21{ }^{\circ} \mathrm{C}\end{array}$ & $\begin{array}{c}\text { Air temperature } \\
38^{\circ} \mathrm{C}\end{array}$ \\
\hline SBMP & $33.5 \pm 11.9(32) \mathrm{aB}$ & $41.1 \pm 16.5(21) \mathrm{bA}$ \\
\hline $\mathrm{SB}$ & $38.8 \pm 14.9(23) \mathrm{aAB}$ & $42.4 \pm 17.3(24) \mathrm{aA}$ \\
\hline $\mathrm{PB}$ & $44.3 \pm 15.6(22) \mathrm{aA}$ & $51.8 \pm 12.6(29) \mathrm{aA}$ \\
\hline
\end{tabular}

$(N)=$ number of specimens; different upper case letters for columns: significant $(p<0.05)$; different lower case letters for rows: significant $(p<0.05)$. 


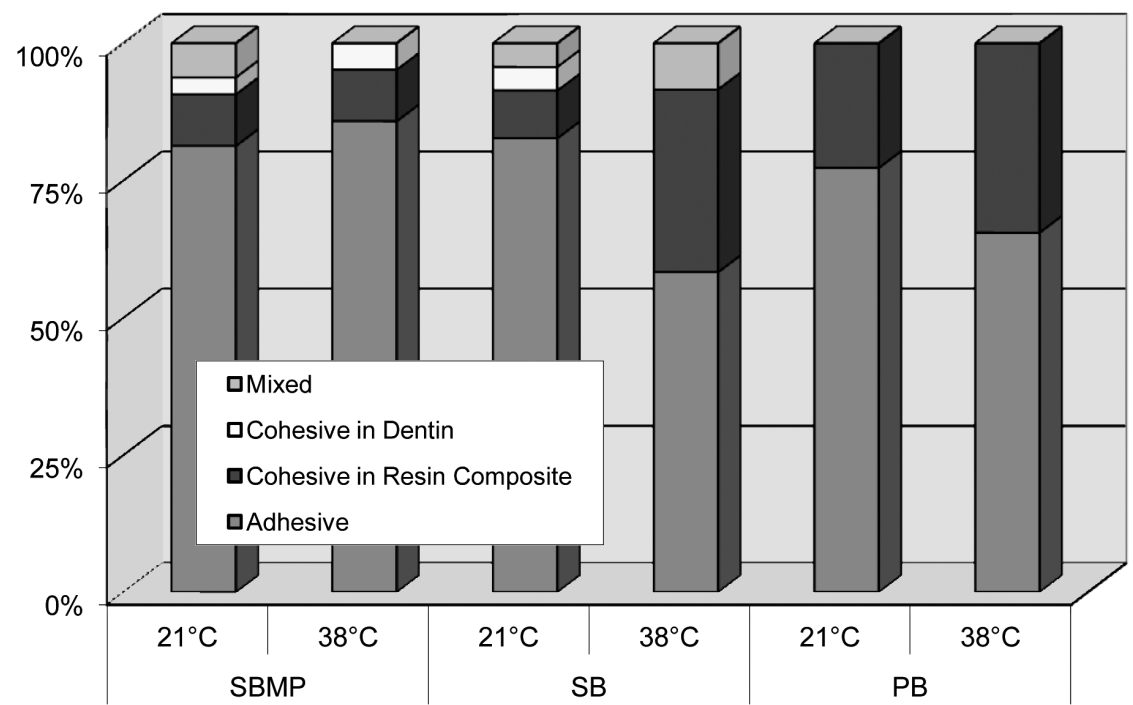

Figure 1- Graphed presentation of proportional incidences of failure modes for all experimental groups as a function of the temperature $\left(21^{\circ} \mathrm{C}\right.$ and $\left.38^{\circ} \mathrm{C}\right)$. SBMP: Adper Scotchbond Multi Purpose; SB: Adper Single Bond 2; PB: Prime \& Bond 2.1. and-rinse adhesive; the first step involved etching and rinsing to remove the smear layer, exposing the collagen network. ${ }^{15}$ Subsequently, priming favored wetting of the etched surface by the applied resin layer. The BisGMA and HEMA-based bonding resin then sealed the dentinal surface and provided an interface for bonding to the composites. This adhesive system contains water and ethanol as solvents. Water is a polar solvent with a high dielectric constant, and is capable of breaking hydrogen bonds between collagen fibrils. ${ }^{16}$ Water is capable of re-expanding the collapsed and shrunken collagen network. ${ }^{17}$ Its dissolving capacity is greatly determined by its ability to form strong hydrogen bonds. However, water is a poor solvent for hydrophobic monomers. This is why solvents such as ethanol or acetone are added to the solution. It has been demonstrated that monomers, such as HEMA decrease the vapor pressure of water even more, which may interfere with the removal of any residual water. ${ }^{18}$ Additionally, the excess water in the adhesive resin compromises the bond strength of adhesives due to entrapment of water in the collagen network. ${ }^{19}$

Ethanol is also a polar solvent that forms hydrogen bonds with its solutes. However, its dielectric constant is lower than that of water, and it is therefore more suitable for the dissolution of less polar solutes..$^{16}$ Additionally, its higher vapor pressure provides better evaporation by air-drying. ${ }^{5}$ Usually ethanol is a co-solvent for water in most adhesives. Water-alcohol mixtures are known to form hydrogen bonds between their molecules, which results in a greater evaporation of water-ethanol aggregates than of pure water. ${ }^{20}$ The presence of ethanol has been claimed to be less critical in the formation of imperfections within the hybrid layer when compared to acetone-based materials. ${ }^{21}$ Acetone presents higher vapor pressure $\left(184 \mathrm{~mm} \mathrm{Hg}\right.$ at $\left.20^{\circ} \mathrm{C}\right)$ when compared with ethanol (43.9) and water (17.5). ${ }^{22}$ Acetone-based adhesives normally present a lower monomer-solvent ratio, ${ }^{21}$ which would require the application of more layers in order to obtain a sealed bonding interface with the same amounts of monomers. Both the vapor pressure and ebullition temperature of acetone are lower than those observed with other solvents, which translates into faster evaporation of the solvent for acetone-based adhesives in clinical settings. Based on this assumption, similar profiles would be expected for acetone-based DBA when applied to dentin substrate, regardless of the adhesive formulation. However, an acetone-based adhesive was reported to exhibit a significant spontaneous evaporation profile only after 5 minutes of its application, which is clinically unacceptable. These results show that, even though the solvent is considered an essential factor, other components present in the adhesive formulation also affect the evaporation time.

It is also important to highlight the influence of the dentin matrix acting as a physical barrier on the solvent evaporation. Solvent evaporation is facilitated and expedited by using warm air rather than air at room tempera- 
ture. The results of the present study proved that bond strength for the 2-step, etch-and-rinse adhesives was not influenced by the air temperature. Despite the slight discrepancies in the mean values of bond strength, it can be stated that solvent evaporation at increased temperature was not an important clinical concern for SB or PB. Conversely, bonding to dentin was significantly increased for the water-based SBMP adhesive when the solvent was evaporated at a higher temperature $(\mathrm{p}<0.05)$. Thus, the first hypothesis (bonding to dentin would be similar when the solvents were evaporated at room temperature [control group] or at a warmer temperature $\left[38^{\circ} \mathrm{C}\right]$ ) was partially supported.

The second hypothesis (bond strength would be similar for all the adhesive systems, irrespective of the airstream temperature) was also partially supported. The bond strength means were not significantly different at $38^{\circ} \mathrm{C}$ which was in agreement with results reported in a previous study. ${ }^{23}$ In that study, an increase in bond strength to dentin was noted for SB only when evaporation was performed at $60^{\circ} \mathrm{C}$, whereas a higher evaporation rate was observed at room temperature $\left(21^{\circ} \mathrm{C}\right)$ for $\mathrm{PB} .{ }^{23}$ The increase in bond strength for SBMP at $38^{\circ} \mathrm{C}$ was possibly due to the higher rate of evaporation of water and the low vapor pressure of water (approximately $23 \mathrm{~mm} \mathrm{Hg}$ ), resulting in easier evaporation. ${ }^{24}$

The fracture mode of failure also varied between both groups (Figure 1). An increase in the incidence of cohesive failure was noted when the temperature used to evaporate the solvent was $38^{\circ} \mathrm{C}$. This change in the fracture pattern explains the slight increase in the mean value of bond strength due to greater solvent evaporation. The increase in bond strength has been attributed to the increase in bonding to dentin at higher temperatures because of the reduced numbers of pores within the adhesive layer, as seen by scanning electron microscopic (SEM) imaging. ${ }^{23}$ A significant negative correlation between the number of adhesive failures and bond strength was also observed. ${ }^{25}$

7. Tay FR, King NM, Chan KM, Pashley DH. How can nanoleakage occur in self-etching adhesive systems that demineralize and infiltrate simultaneously? J Adhes Dent. 2002 Winter;4(4):255-69.

8. Hotta M, Kondoh K, Kamemizu H. Effect of primers on bonding agent polymerization. J Oral Rehabil. 1998 Oct;25(10):792-9.
The duration of evaporation of solvents has been also reported to influence the bond strength. ${ }^{25}$ Solvents can only be effective in the optimization of the bonding procedures when a reasonable period of time is given for evaporation. On the other hand, some adhesives are insensitive to variations in air-drying duration; but in general, shorter air-blowing times lead to lower bond strength. ${ }^{25}$ Clinicians should be aware of the solvent present in adhesives to guarantee the best clinical performance of their bonded restorations.

\section{Conclusions}

Under the conditions of the present study, it can be concluded that:

- Only the water-based adhesive system (SBPM) is influenced by the temperature at which the solvent was evaporated.

- Bonding to dentin at room temperature is materialdependent.

\section{References}

1. Nunes TG, Garcia FC, Osorio R, Carvalho R, Toledano M.Polymerization efficacy of simplified adhesive systems studied by NMR and MRI techniques. Dent Mater. 2006 Oct;22(10):96372 .

2. Reis A, Klein-Junior CA, de Souza FH, Stanislawczuk R, Loguercio AD. The use of warm air stream for solvent evaporation: effects on the durability of resin-dentin bonds. Oper Dent. 2010 JanFeb;35(1):29-36.

3. Ikeda T, De Munck J, Shirai K, Hikita K, Inoue S, Sano H, et al. Effect of evaporation of primer components on ultimate tensile strengths of primer-adhesive mixture. Dent Mater. 2005 Nov;21(11):1051-8.

4. Wang Y, Spencer P. Hybridization efficiency of the adhesive/dentin interface with wet bonding. J Dent Res. 2003 Feb;82(2):141-5.

5. Yiu CK, Pashley EL, Hiraishi N, King NM, Goracci C, Ferrari M, et al. Solvent and water retention in dental adhesive blends after evaporation. Biomaterials. 2005 Dec;26 (34):6863-72.

6. Van Meerbeek B, De Munck J, Yoshida Y, Inoue S, Vargas M, Vijay $\mathrm{P}$, et al. Buonocore memorial lecture. Adhesion to enamel and dentin: current status and future challenges. Oper Dent. 2003 May-Jun;28(3):215-35.

9. Jacobsen T, Soderholm KJ. Some effects of water on dentin bonding. Dent Mater. 1995 Mar;11(2):132-6. 
10. Paul SJ, Leach M, Rueggeberg FA, Pashley DH. Effect of water content on the physical properties of model dentine primer and bonding resins. J Dent. 1999 Mar;27(3):209-14.

11. Hashimoto M, Tay FR, Svizero NR, de Gee AJ, Feilzer AJ, Sano H, et al. The effects of common errors on sealing ability of total-etch adhesives. Dent Mater. 2006 Jun;22(6):560-8.

12. Cardoso Pde C, Loguercio AD, Vieira LC, Baratieri LN, Reis A. Effect of prolonged application times on resin-dentin bond strengths. J Adhes Dent. 2005 Summer;7(2):143-9.

13. Spreafico D, Semeraro S, Mezzanzanica D, Re D, Gagliani M, Tanaka T, et al. The effect of the air-blowing step on the technique sensitivity of four different adhesive systems. J Dent. 2006 Mar;34(3):237-44.

14. Garcia FC, Almeida JC, Osorio R, Carvalho RM, Toledano M. Influence of drying time and temperature on bond strength of contemporary adhesives to dentine. J Dent. 2009 Apr;37(4):315-20.

15. Yoshioka M, Yoshida Y, Inoue S, Lambrechts P, Vanherle G, Nomura $\mathrm{Y}$, et al. Adhesion/decalcification mechanisms of acid interactions with human hard tissues. J Biomed Mater Res. 2002 Jan;59(1):56-62.

16. Van Landuyt KL, Snauwaert J, De Munck J, Peumans M, Yoshida Y, Poitevin A, et al. Systematic review of the chemical composition of contemporary dental adhesives. Biomaterials. 2007 Sep;28(26):3757-85.

17. Carvalho RM, Mendonca JS, Santiago SL, Silveira RR, Garcia FC, Tay FR, et al. Effects of HEMA/solvent combinations on bond strength to dentin. J Dent Res. 2003 Aug;82(8):597-601.

18. Garcia FCP, Wang L, Pereira LCG, de Andrade e Silva SMAE, Marquezini Junior L, Carrilho MRO. Influences of surface and solvent on retention of HEMA/mixture components after evaporation. J Dent. 2010 Jan;38(1):44-9.

19. Garcia G, Fernandes KB, Garcia FC, D’Alpino PH, da Rocha Svizero N, Wang L. Solvent retention of contemporary commercial dentin bonding agents in a demineralized dentin matrix. Eur J Dent. 2010 Jul;4(3):293-7.

20. Moszner N, Salz U, Zimmermann J. Chemical aspects of selfetching enamel-dentin adhesives: a systematic review. Dent Mater. 2005 Oct;21(10):895-910.

21. Reis AF, Oliveira MT, Giannini M, De Goes MF, Rueggeberg FA. The effect of organic solvents on one-bottle adhesives' bond strength to enamel and dentin. Oper Dent. 2003 NovDec;28(6):700-6.

22. Gallo JR, Burgess JO, Xu X. Effect of delayed application on shear bond strength of four fifth-generation bonding systems. Oper Dent. 2001 Jan-Feb;26(1):48-51

23. Klein-Junior CA, Zander-Grande C, Amaral R, Stanislawczuk R, Garcia EJ, Baumhardt-Neto R, et al. Evaporating solvents with a warm air-stream: effects on adhesive layer properties and resindentin bond strengths. J Dent. 2008 Aug;36(8):618-25.

24. Lima FG, Moraes RR, Demarco FF, Del Pino FA, Powers J. Onebottle adhesives: in vitro analysis of solvent volatilization and sealing ability. Braz Oral Res. 2005 Oct-Dec;19(4):278-83.

25. Furuse AY, Peutzfeldt A, Asmussen E. Effect of evaporation of solvents from one-step, self-etching adhesives. J Adhes Dent. 2008 Feb;10(1):35-9. 